Revista de Filosofía y Teoría Política, n. ${ }^{\circ}$ 48, 2017, e013, ISSN 2314-2553

Universidad Nacional de La Plata.

Facultad de Humanidades y Ciencias de la Educación.

Departamento de Filosofía

\title{
La gravitación de ciertos conceptos sorelianos en el pensamiento de Mariátegui
}

\author{
The gravitation of certain Sorelians concepts in the thought of \\ Mariátegui
}

\section{Matías Zucconi}

Facultad de Humanidades y Ciencias de la Educación-Universidad Nacional de La Plata, Argentina | matiasz@live.com

\section{PALABRAS CLAVE RESUMEN}

Mito El concepto de mito revolucionario es la idea de Georges Sorel más influyente en el pensamiento de José Carlos Mariátegui. Sin embargo, este concepto no funciona de la misma forma en ambos autores, Marxismo fundamentalmente porque es aplicado en cada caso a coyunturas nacionales marcadamente diferentes, Socialismo como las de Francia y Perú a principios del siglo XX. Por esta razón resulta importante, con independencia de las similitudes teóricas, diferenciar entre un mito expresado como huelga general,

Proletariado ligado al proletariado industrial europeo, y otro caracterizado en torno a la revolución social, ligado a las masas del campesinado indígena. En ambos casos vemos que este tipo de conceptos son funcionales a una ampliación de los límites del marxismo más allá del estalinismo y la III Internacional.

\section{KEYWORDS ABSTRACT}

Myth The concept of "revolutionary myth" is the idea of Georges Sorel most influential in the thinking of Marxismo José Carlos Mariátegui. However, this concept does not work the same way in both authors, mainly because it is applied in each case on markedly different national situations, such as France and Peru in

Socialismo the early twentieth century. For this reason it is important, regardless of the theoretical similarities,

Proletariat expressed as the difference between a general strike myth, linked to European industrial proletariat, and another characterized around the social revolution, linked to the masses of the indigenous

Indigenous peasantry peasantry. In both cases we see that such concepts are functional to an extension of the limits of Marxism beyond Stalinism and the III International. 


\section{Introducción}

El objetivo de este trabajo es analizar la recepci ón que realiza el autor peruano José Carlos Mariátegui respecto de ciertas ideas esbozadas por el intelectual francés Georges Sorel. En primer lugar, nos concentramos en dar cuenta de las características de un concepto fundamental en la obra soreliana como es el de mito revolucionario, que luego tiene una funcionalidad central en el pensamiento mariateguiano. En este sentido, nos interesa resaltar las diferentes inflexiones que adquiere este concepto en cada autor, de acuerdo al contexto histórico y sociopolítico en el que escriben, así como también subrayar el modo en que esta recepción teórica le permite a Mariátegui ampliar el horizonte de análisis de su perspectiva marxista, hacia una postura heterodoxa e incluso espiritualista, con importantes diferencias con respecto al marxismo planteado por la III Internacional y el estalinismo. Para trabajar estos temas nos basamos en las Réflexions sur la violence de Sorel ${ }^{1}$ y en los Siete ensayos de interpretación de la realidad peruana de Mariátegui ${ }^{2}$, además de considerar algunos ensayos previos del Amauta, resultado de su producción intelectual en periódicos y revistas peruanas.

\section{Debates previos en torno a la recepción mariateguiana de Sorel}

Varios trabajos críticos se han abocado a discutir el grado de influencia del pensamiento de Sorel en la obra de Mariátegui. Una de las elaboraciones más importantes, en este sentido, puede apreciarse en la compilación que hace José Aricó (1980) del debate que al respecto mantienen, a través de sus artículos, Robert Paris (1970 y 1971) y Luis Villaverde Alcalá-Galiano (1971). De acuerdo con Paris (1970), la presencia del mito soreliano en Mariátegui es una "verdadera incursión por lo imaginario” (1980, p.125), al no apelar a las facultades racionales de las multitudes. Por lo demás, Paris considera que la recepción de Sorel por parte de Mariátegui no responde a "una pasión del período juvenil” (1980, p. 127), ya que puede rastrearse en diferentes etapas de su obra $\underline{3}$. Según Paris, Sorel aparece como introductor de ciertas temáticas que pueden ayudar al Amauta a pensar mejor el socialismo y su competencia como movimiento político y cultural con injerencia en las masas. No obstante, éste es el alcance que Paris ve en la relación Sorel-Mariátegui, o en lo que el marxismo de Mariátegui tiene de soreliano, y de ningún modo reconoce entre ellos un seguimiento de alumno a maestro.

Por otro lado, Villaverde (1971) advierte que la obra en la que mejor puede rastrearse la influencia soreliana, en el autor peruano, es la compilación de El alma matinal..., y sobre todo en el breve ensayo "El hombre y el mito". Villaverde afirma que en ese artículo "Mariátegui se muestra más sorelista que en ningún otro” (1980, p. 148). Entrando en discusión con el escrito de Paris, sentencia que el Amauta "traduce al pie de la letra" las ideas de su maestro Sorel, aunque no como lo haría un traductor, sino reinterpretando las enseñanzas del francés. Además, Villaverde sostiene que Paris compara incorrectamente el mito con la imaginación, cargando a ésta con una connotación negativa (1980, p. 149). En definitiva, lo que intenta explicar Villaverde es que el mito mariateguiano de la revolución social es la traducción del mito soreliano de la huelga general, ya que ambos tienen en cuenta un conflicto capaz de hacer tambalear -tal vez definitivamente- las estructuras del capitalismo. Esto contradice a Paris, quien sostiene que el hecho de no presentar la huelga general como una opción tiene que ver con que Mariátegui comprende que por sus cualidades -y por el propio trabajo que realiza-, el sujeto social revolucionario en el Perú no puede ser movilizado por 
un mito propio del proletariado de estilo fabril y europeo. Además, siguiendo la idea de la traducción al pie de la letra, Villaverde advierte que, si se leen ciertos pasajes de Mariátegui y las Reflexiones... de Sorel, el estilo y el tratamiento de ciertos temas son tan similares entre ambos autores que se vuelve evidente la influencia innegable del francés sobre el peruano (1980, p. 154).

En una respuesta crítica con la cual coincidimos, Paris (1971) le cuestiona a Villaverde el señalamiento de esa relación jerárquica entre maestro y discípulo. Además, tal como advierte Paris, enfatizar la influencia de Sorel de manera exclusiva conduce a eclipsar la recepción de otros autores y movimientos igualmente importantes, porque juegan un papel ineludible en la definición de la creatividad del marxismo mariateguiano (Paris, 1980, p. 159). Pues ¿cómo ignorar el peso que tienen, en el autor peruano, los desarrollos del indigenismo de los años veinte, y y los artículos del joven Gramsci y del ordinovismo italiano en su conjunto, como corriente ideológica?

Partiendo entonces de este debate crítico entre intelectuales que recogen la recepción mariateguiana de ciertos aspectos del pensador francés, en este trabajo nos proponemos analizar críticamente cuáles son los conceptos que Mariátegui en verdad aprecia de la obra soreliana, y qué gravitación tienen en el análisis filosófico-político que, desde el socialismo, realiza acerca de la coyuntura social del Perú de su tiempo.

\section{De Sorel a Mariátegui}

En la obra del intelectual francés Georges Sorel, defensor acérrimo del movimiento obrero-sindical de su país, existe una premisa clara: el mito concuerda con los intereses y los objetivos del socialismo. Pero entonces, ¿qué es para este autor un mito y qué función cumple en la lucha de clases?

Aunque en las Reflexiones... Sorel se refiere a la naturaleza y a la función del mito a lo largo de todo el ensayo, se concentra especialmente en este problema en el cuarto capítulo, titulado "La huelga proletaria”. Allí, luego de exponer su descreimiento respecto de cualquier tipo de determinismo (en especial, de aquel que presupone que indefectiblemente el capitalismo y la burguesía sucumbirán, gracias al engendramiento de una clase destinada a superarlos), advierte cómo el advenimiento de la liberación -o de la ampliación de derechos- del proletariado sólo puede darse de acuerdo a ciertos mecanismos de acción de los trabajadores, y cómo esa acción puede ser motivada por los mitos, como "construcciones de un porvenir indeterminado en el tiempo" (Sorel, 2005, p. 178), eficaces para canalizar las tendencias más fuertes de un pueblo o de una clase. Estas tendencias "se ofrecen a la mente con la insistencia de instintos" (Sorel, 2005, p.178) que surgen de determinadas circunstancias de la vida cotidiana y que dan confianza en la acción próxima, al basarse en una reforma de la voluntad. Los mitos no le impiden al sujeto proseguir con sus tareas normales; sólo crean una cierta predisposición sentimental de acuerdo a las situaciones vividas ${ }^{4}$.

El mito por excelencia, que Sorel rescata para el proletariado, es el de la huelga general. Y no importa la posibilidad real de concreción de éstaéstaesta, sino más bien el mito en sí mismo: lejos de ser una predicción científica, el énfasis se ubica en que funcione como predisposición latente de los sentimientos, del ánimo, de la voluntad del proletariado hacia el mejoramiento de sus condiciones materiales y espirituales. Es necesario que el mito, que siempre es movilizador del 
espíritu, se sitúe en concordancia con las premisas básicas del socialismo. Así se cumple con una función de reminiscencia, pues la hipótesis de Sorel es que, a lo largo de la historia, son las grandes huelgas los conflictos que, como muestras irrefutables de la lucha de clases, han generado cierto cambio en el panorama sociopolítico, consiguiendo en ciertos casos una ampliación de derechos para las clases oprimidas. El historial exitoso de las huelgas es lo que se presenta, en la conciencia del proletariado contemporáneo, como un impulso. Las masas industriales reciben representaciones eficaces con "la facultad de identificarse con su concepción socialista”; en esas representaciones confluyen "la razón, las esperanzas y la percepción de los hechos particulares” (Sorel, 2005, p.181).

Por otra parte, el mito no permite predecir futuros enfrentamientos: "resulta inútil razonar acerca de los incidentes que puedan producirse en el curso de la guerra social, y acerca de los conflictos decisivos que pueden darle la victoria al proletariado" (Sorel, 2005, p.180). El mito es una unidad intuitiva devenida del recuerdo de conflictos pasados; un conjunto que aporta esperanzas y que moviliza a la acción revolucionaria, pero que no permite prever los hechos; es un medio de actuar sobre el presente.

Si tomamos, como condición prioritaria e ineludible del socialismo, la liberación del proletariado (respecto de la opresión económica, política y cultural que éste éste este sufre, bajo las condiciones de producción capitalista), el mito de la huelga general es efectivo en tanto puede llegar a movilizar a la clase hacia la acción (de la huelga) que intenta subvertir la naturalidad de la posición de dominación que ejerce la burguesía, creando así un nuevo orden de poder sociopolítico y económico. Para Sorel, el mito, en el cual se encuadra el socialismo, es "una organización de imágenes capaces de evocar de manera instintiva todos los sentimientos que corresponden a las diversas manifestaciones de la guerra entablada por el socialismo contra la sociedad moderna" (2005, p. 181). Así, se puede ver que la potencia del mito proviene de su anclaje en el plano psicológico, afectivo --e incluso inconsciente- del proletariado.

Con respecto a la formación del mito, Sorel advierte que las diversas huelgas históricas van engendrando en los proletarios sensaciones contundentes que los mueven a la unión y la organización; la evocación de anteriores conflictos y de reivindicaciones "anima con intensa vida todos los detalles del conjunto presentado a la conciencia” (2005, p. 182), operando como creación de una cierta disposición mental que lleva a los proletarios a pensar que pueden oponerse a los patrones, uniéndose a sus iguales.

Para Sorel, el mito no puede transmitirse a través del lenguaje académico, y acaso ni siquiera puede transmitirse por medio del lenguaje: se capta de modo instantáneo como un conjunto, como una intuición; por eso opera en el plano afectivo, sin ser captado por medio de argumentos discursivos racionales, sino a través de la impresión que provoca, en el proletariado, la apreciación concreta de diversos hechos conflictivos que han alterado el orden establecido por la sociedad capitalista. Así, el autor afirma que

...las huelgas han engendrado en el proletariado los más nobles sentimientos, los más hondos y los que más mueven; la huelga general los agrupa a todos en un conjunto y, al relacionarlos, a cada uno de ellos le confiere su máxima intensidad; al apelar a punzantes recuerdos de conflictos particulares, anima con intensa vida todos los detalles del conjunto presentado a la conciencia. Así obtenemos esa intuición del socialismo que el lenguaje no podía expresar de modo perfectamente claro: y la obtenemos en forma de 
un conjunto que se capta instantáneamente (Sorel, 2005, pp.: 181-182).

Resulta clave, en el enfoque de Sorel, el peso otorgado a las imágenes mediante las cuales se transmite el mito de la huelga general. El mito es un elemento que cala en la faceta irracional e instintiva de las masas proletarias y que, a partir de allí, se disemina por las mismas vías por las cuales, para Angenot (2010b), se disemina la propaganda socialista. La idea de "huelga general”, transmitida a las masas, persuade de manera propagandística, logrando "sacudir la apatía, la ataraxia del auditorio; (...) debe entonces representar en su discurso la mímesis de las emociones susceptibles de movilizar al destinatario, de hacerlo salir de su indiferencia” (Angenot, 2010b, p. 173). En este sentido, Sorel piensa que el mito desencadena lo que Angenot llama "movimientos del pathos": una reacción no racional en tanto puede "electrizar, embriagar, exaltar, indignar” a las multitudes (Angenot, 2010b, pp. 173-174). Los recuerdos, los antecedentes de las huelgas anteriores, como enfrentamientos puntuales con la burguesía y la fuerza del Estado capitalista, cumplen, en las mentes del proletariado, una función persuasiva que predispone a los individuos a adoptar una actitud confrontativa. La propaganda de la huelga le da sentido al mito y a su objetivo de expansión; la huelga en sí -como fenómeno del que se tiene constancia y que podría producirsees el mejor factor de enseñanza para el obrero (Angenot, 2010b, p.166): el mito de la huelga general prepara al proletariado y le otorga una noción heroica, asociándolo con una obra "grave, temible y sublime" como el socialismo, y sólo por eso ha de ser considerada como de un inestimable valor (Sorel, 2005, pp. 194-195).

Para promover la idea de la huelga general, Sorel apela a términos que traen consigo un sentido imaginativo, como el de la "estela" revolucionaria, elemento que puede ser repensado a partir del análisis de Angenot sobre el "gran relato militante" como "movilizador, porque implica una difusión geométrica, un contagio fatal y rápido...” (2010b, p 160). En ese sentido, Sorel busca presentar el mito, que "arrastra todo lo que toca”, apuntando a la afectación psicológica del proletariado para predisponerlo hacia la acción revolucionaria:

Para Sorel la función del mito no consiste en estabilizar, sino en dirigir unas energías e inspirar una acción. Esto lo hace dando forma a una visión dinámica del movimiento vital, tanto más potente cuanto que no es racional y en consecuencia no está sujeta a la crítica y refutación de los sabelotodos universitarios. Un mito se compone de imágenes “cálidamente coloreadas", y afecta a los hombres no como lo hace la razón, la educación de la voluntad o el mando de un superior, sino a manera de un fermento del alma que engendra entusiasmo e incita a la acción, y, si ello fuera necesario, al desorden. Los mitos no necesitan realidad histórica; dirigen nuestras emociones, movilizan nuestra voluntad, dan sentido a cuanto somos y hacemos (Berlin, cf. en Sorel, 2005, p.: 38).

Cabe destacar que el hecho de considerar la movilización de las masas en términos que apelan a lo sentimental-afectivo forma parte de un clima de época, ya que tan sólo una década antes del texto de Sorel aparece la Psychologie des foules de Gustave Le Bon ${ }^{5}$, ensayo que aborda la intervención de las multitudes populares en los movimientos políticos, a partir de las emociones que despierta, en el auditorio, cierta disposición a la acción, a la intervención en la esfera de lo público. Por supuesto, 
la valoración de este fenómeno es muy diversa en estos dos autores. Mientras Le Bon detecta la situación de manera problemática, ideando formas de manipulación colectiva y de coerción, en la obra de Sorel esto se evalúa con total positividad, puesto que justamente se busca la intervención directa del proletariado en la política, como un suceso marcadamente revolucionario.

Además, tal como podemos leer en su obra $\underline{6}$, Sorel considera que el sindicato, agrupación exclusivamente obrera, es el instrumento que mejor organiza esa resistencia en la que se fomenta el mito de la huelga general. Para que este sindicalismo pueda generar una posición estable, dentro del panorama político, es necesaria la existencia de una fuerte y próspera industria de la que el proletario sea el productor: "importa mucho poner de relieve esa característica de elevada prosperidad que ha de poseer la industria para permitir la realización del socialismo” (Sorel, 2005, p.1). El razonamiento de Sorel es claro: si la fortaleza de la industria y la ganancia capitalista, a costa del trabajo proletario, deriva en la creación de sindicatos como ámbitos de protección y promoción de derechos de la clase obrera ante los patrones, entonces el sindicalismo es fruto de la propia dinámica del progreso industrial. Obviamente, no deja de surgir la pregunta acerca de cuál sería el destino del socialismo en países en los que no se observa un desarrollo industrial tan vigoroso como en la Francia de Sorel, e incluso en países con una apenas incipiente industrialización. Como veremos, este interrogante resulta clave en países periféricos como Perú.

En el contexto peruano de la década del veinte, la figura de Mariátegui surge como la de un escritor con la intencionalidad de otorgar una fuerte base empírica a su bagaje conceptual marxista. La asunción del problema de la tierra como fundamento de la dominación económico-social inter-clase, la aceptación de la preponderancia de un sujeto social no convencional para la historia del socialismo, o incluso la cuestión de la nacionalidad y de la ideología política son claras muestras de ello. Porque en Perú, “el universo indígena fue desde el principio de su historia la realidad dominante” (Aricó, 1980, p. XLIII), realidad que históricamente fue invisibilizada por la intelectualidad local, al menos hasta la aparición de la obra del intelectual anarquista Manuel González Prada ${ }^{7}$. Y en franca oposición a la forma de considerar lo nacional desde parámetros eurocéntricos, en el intento de acercar indigenismo y socialismo, se halla "el nudo esencial, la problemática decisiva, el eje teórico y político en torno al cual Mariátegui articuló toda su obra de crítica socialista de los problemas y de la historia del Perú”, tal como advierte Aricó (1980, p.: XLVIII).

Ahora bien, en el encuentro con nuevas fuentes de inspiración, el Amauta inicia un proceso de alejamiento de la ortodoxia canonizada desde Europa con la transición entre la II y la III Internacional Comunista (que comienza previamente, y se sistematiza luego de la muerte de Mariátegui). Cabe aclarar que la II Internacional se funda en 1889 para coordinar la actividad de los diversos partidos socialistas o laboristas alrededor del mundo. Pasadas la Revolución Rusa (1917) y la Primera Guerra Mundial (1914-1918), esta organización comienza a mostrar contradicciones internas, y en 1919 surge la III Internacional o Internacional Comunista (Comintern) que busca diferenciarse de su predecesora, rechazando el apego a los medios electorales y optando por la vía revolucionaria, en un intento de "bolchevización” que recorre toda la década del veinte (y que tendrá cierto impacto incluso en América Latina, entre figuras radicalizadas vinculadas inicialmente a la Reforma Universitaria). La gravitación de la III Internacional, a escala mundial, es aglutinante, 
pues convoca a todos los partidos socialistas de corte revolucionario en primera instancia, pero también les exige ciertas condiciones a las organizaciones adherentes. Esto se combina con una fuerte institucionalización, regida por el Partido Comunista de la Unión Soviética, que mantiene el eje directivo a escala internacional a través de un marxismo ortodoxo con pretensiones obreristas, ponderando la supremacía del proletariado como clase revolucionaria por excelencia, y fomentando el desarrollo capitalista-industrial como condición necesaria para emprender la marcha hacia el socialismo, lo que presenta un serio problema para países con un medio predominantemente rural. En 1924, la III Internacional funda el Secretariado Sudamericano, órgano rector de las funciones directrices de los partidos alineados en América Latina. Mariátegui, en su rol de intelectual marxista

-en especial a partir de su regreso de Europa, y a la luz de sus investigaciones sobre la realidad nacional-, al igual que el Partido Socialista Peruano, fundado por él, se ubican en una línea marxista creativa, atenta a las problemáticas coyunturales y a los sectores populares nacionales y sus demandas, entrando así en discusión con la institucionalización dogmática impulsada por el comunismo soviético. Esto puede verse demostrado cuando los puntos de vista del Amauta son duramente criticados con ocasión de la Primera Conferencia Comunista Latinoamericana, realizada en 1929 en Buenos Aires ${ }^{-}$. Finalmente, Mariátegui fallece prematuramente en 1930. Lo que sigue durante la década del treinta, e incluso llega hasta el momento en que se produce Revolución Cubana en 1959, es un período de imposición de la "ortodoxia estalinista” en los debates teóricos y en los ejes directivos del marxismo, alineando a los diferentes partidos hacia las necesidades del movimiento comunista internacional $\underline{\underline{9}}$.

Mariátegui desacuerda especialmente con respecto a la presunción evolucionista y fatalista, sostenida por la Internacional. El resultado de esta contraposición se traduce en el rechazo de toda pasividad sociopolítica por parte de los actores involucrados, en base a lo cual -según Aricó-, “colocaba en el centro el problema de la revolución y del partido, es decir el problema de la transformación social y política y de la organización de las fuerzas capaces de realizarlas” (1980, p. $\mathrm{XVI)}$.

De esta manera, surge el interrogante sobre cómo hacer para que las masas vuelvan a asumir un rol social transformador, en un contexto mundial en donde el marxismo tiende a convertirse en un esquema de leyes rígidas, invariables y mecánicas.

El primer paso de Mariátegui, bajo la influencia del historicismo italiano (con el cual entra en contacto durante su estadía en Italia), consiste en revalorizar la voluntad humana y la moral, lo que también implica recuperar la concepción de la clase trabajadora como sujeto social, y al trabajador como un sujeto individual (no como un mero engranaje de una maquinaria predeterminada). El sujeto de Mariátegui piensa y siente, y es sobre todo dueño de una psicología capaz de asumir, con consciencia, su situación como individuo y como parte de una clase. Sin embargo, Mariátegui se enfrenta con un campesinado e incluso con un proletariado urbano que, en términos de movimiento, está todavía en ciernes, en proceso de construcción. Por ello, su actividad teórico-práctica "fue en cierto modo fundacional antes que dirigente” (Aricó, 1980, p. XVII).

Si el indio se encuentra privado de su derecho a la propiedad de la tierra, dedicado a trabajos sumamente precarizados, y excluido de la nacionalidad, debe advertir esas situaciones como 
individuo y, por lo tanto, también como clase. Por ende, en la psicología, en la moral y fundamentalmente en el reconocimiento espiritual de las condiciones materiales más urgentes de la clase, puede residir su capacidad y su disposición en favor de su propia redención: "un pueblo de cuatro millones de hombres, consciente de su número, no desespera nunca de su porvenir” (Mariátegui, 2007, p. 38).

Mariátegui reclama por una organización de las masas que las conduzca de la pasividad al protagonismo, porque del mismo modo en que les reconoce una potencia creadora, admite que "a los indios les falta vinculación nacional” para dejar de ser una "muchedumbre dispersa” incapaz de decidir su rumbo histórico (2007, p. 38). En este sentido, el autor comprende que el campesinado indígena presenta -aunque de manera incipiente- las características de un movimiento social determinado, y que, tal como advierte Aricó (1980, pp.: XLVI-XLVII), la suerte del socialismo peruano depende de su capacidad de irrupción en la vida nacional como una fuerza “autónoma”.

En este punto del pensamiento mariateguiano, cobra suma importancia la recepción de la tesis de Sorel sobre el mito revolucionario, presente tanto en artículos diversos como en los Siete ensayos.... No obstante, esta lectura que hace el Amauta forma parte de un contexto de recepción más amplio, puesto que las ideas del autor francés también son influyentes en las reflexiones de escritores ligados a la Reforma Universitaria (1918) y a una creciente radicalización política, incluso de figuras relacionadas con posiciones sorelianas desde una perspectiva anarco-bolchevique (como los jóvenes Carlos Astrada, Deodoro Roca o Saúl Taborda) $\underline{10}$.

En “El hombre y el mito” (publicado originalmente en la revista Mundial de Lima en 1925, y luego compilado en 1950 en El alma matinal y otras estaciones del hombre de hoy, en la sección "La emoción de nuestro tiempo”), Mariátegui cita explícitamente el concepto soreliano de “mito”, subrayando la capacidad del mismo para la organización de la voluntad colectiva. Allí advierte que la sociedad burguesa ha alcanzado un nivel de racionalización y mecanización tendiente a ahogar cualquier vestigio de voluntarismo, conduciendo al borramiento y la alienación de las acciones más humanas; por eso "la civilización burguesa sufre la falta de un mito” (Mariátegui, 2010, p. 181). Los dos grandes paladines de la sociedad moderna -la razón y la ciencia-descartan la presencia de los antiguos mitos y, en consecuencia, enaltecen la figura del progreso a través de la producción económica y de la tecnificación. Ese progreso se logra a costa de la imposición de una clase sobre la otra, lo que, a lo largo de la historia, se ha demostrado por medio de las más feroces perpetraciones. La racionalización, la carrera cientificista y la evolución técnico-tecnológica no bastan para suscitar el mejoramiento concreto de las condiciones materiales del hombre. De aquí Mariátegui infiere la necesidad de algo más: un mito, ya que

...el mito mueve al hombre en la historia. Sin un mito, la existencia del hombre no tiene ningún sentido histórico. La historia la hacen los hombres poseídos e iluminados por una creencia superior, por una esperanza superhumana; los demás hombres son el coro anónimo del drama (Mariátegui, 2010, p.: 182).

Hay una necesidad de creer, una necesidad perentoria de abandonar el escepticismo moderno; el hombre requiere sostener una esperanza que lo lleve a romper con la pasividad. Comprometido con su rol de intelectual reivindicador de las diversas problemáticas sociales de su país, Mariátegui 
afirma que al hombre contemporáneo "hay que proponerle una fe, un mito, una acción” (2010, p. 184).

“El hombre y el mito” busca demostrar cómo el capitalismo burgués conduce a los hombres -y en especial, a quienes se sitúan dentro de las masas trabajadoras- a verse desahuciados sobre la posibilidad de alcanzar su bienestar material y espiritual. La gran idea del progreso indefinido gracias a la potencialidad de la razón (a través de la técnica), que fue el motor que impulsó el desarrollo del capitalismo industrial, ha manifestado indudablemente otra fase de los conflictos y de la explotación de una clase sobre la otra. En cierta forma, este artículo relativiza el alcance del progreso de la sociedad burguesa, al manifestar que, de acuerdo al estado en que se encuentra la clase trabajadora en general, el progreso no ha significado más que pauperización.

Si el mayor rasgo de la sociedad burguesa es la falta de esperanzas que impulsen a las clases menesterosas a movilizarse en torno a la ampliación de sus derechos, entonces el socialismo necesita de un mito, que el Amauta encuentra en la revolución social.

¿Pero por qué proponer un mito en una sociedad y una época más bien tendientes al escepticismo? ¿Será que deben abandonarse las pretensiones científicas para retornar a las motivaciones religiosas? No. Mariátegui no piensa en la restauración del dominio religioso. Tampoco resignaría ninguno de los que considera avances de la sociedad occidental. El problema que encuentra en la modernidad capitalista, lucha de clases de por medio, es que las ideas del progreso científico y técnico se vacían de significado para la clase trabajadora, y la política clásica-liberal ya no puede generar ningún estímulo cultural, económico, etc., que movilice a las masas para encontrar un bienestar superior y para crear nuevas relaciones productivas. Por eso existe, entre los oprimidos, la necesidad urgente de creer en algo que los conduzca a una posición protagónica. El mito de la revolución social aparece en el horizonte como aquello por lo cual entusiasmarse y organizarse. El socialismo es ese gran movimiento que incluye reflexión crítica, difusión masiva y esperanzas en favor de un cambio posible.

En este sentido, el mito revolucionario del socialismo es religioso: el proletario y el campesino (en definitiva, el trabajador) conocen su actual situación material y espiritual, pero adoptan el socialismo en tanto fe que canaliza sus necesidades y sus ansias de vivir mejor. Por ello, Mariátegui afirma que "los motivos religiosos se han desplazado del cielo a la tierra” (2010, p. 185), ya que la emoción revolucionaria es una forma de la emoción religiosa 11 .

El socialismo no es religioso al estilo del catolicismo, que alienta la esperanza de encontrar una mejor vida luego de la muerte (porque ese mito implica pasividad y obediencia): el de la revolución social implica, por el contrario, movilización y conflicto.

Según Mariátegui, en el hombre hay una necesidad de infinito que lo lleva a emplazar mitos, porque la razón y la ciencia no le bastan,; no lo satisfacen completamente. En cierto momento la libertad, la democracia y la paz fueron los mitos con los que se hizo frente al dominio feudal y al absolutismo; con esos mitos, la burguesía les arrebató el dominio político a la monarquía, y el dominio económico a los grandes señores, sentando las bases de la sociedad industrial y del progreso científico (Mariátegui, 2010, pp. 181-182).

Pero el mundo de la burguesía y el capitalismo, tecnificado y burocratizado, ha caído en un período 
de macado marcado escepticismo, que es infecundo, "y el hombre no se conforma con la infecundidad” porque tiene “una exasperada y a veces impotente voluntad de creer” (2010, pp. 182183).

Ahora bien, esa voluntad de creer -que necesita de un mito- es propia del proletariado como clase oprimida, y no puede ser orientada por "la inteligencia burguesa" que "se entretiene en una crítica racionalista del método, de la teoría, de la técnica de los revolucionarios”. Por ende, el mito de la revolución social no puede analizarse en términos intelectualistas, porque no es propio de los intelectuales sino de la clase trabajadora, cuya fuerza no está en su ciencia: “está en su fe, en su pasión, en su voluntad. Es una fuerza religiosa, mística, espiritual” (2010, pp. 184-185). Y por esta pertenencia del mito a la clase trabajadora, Mariátegui sostiene que "los profesionales de la inteligencia no encontrarán el camino de la fe; lo encontrarán las multitudes”. Lo que les queda entonces a los intelectuales es recoger a posteriori las acciones de la clase trabajadora, y reflexionar al respecto (2010, p. 185).

Mariátegui piensa en un mito diferente respecto del soreliano, de acuerdo a la coyuntura particular del Perú, y demuestra una aguda lectura de las Reflexiones..., incluso reproduciendo un pasaje de la "Carta a Daniel Halévy”, sección introductoria al texto del intelectual francés. Además, en su artículo "El hombre y el mito”, cita a Ernest Renan para referirse a la fuerza de voluntad despertada por el mito entre las multitudes socialistas, lo que no es sino más que una re-escritura de un pasaje de Sorel refiriéndose a Renan.

En algunas secciones de los Siete ensayos..., el Amauta se parafrasea a sí mismo, trayendo a colación fragmentos textuales o ampliados de su artículo de 1925. En "El problema de la tierra”, remite varias veces a Sorel, inclusive dando cuenta de los análisis históricos de éste, más allá de las referencias a las Reflexiones... centradas en el papel del mito. Por ejemplo, al analizar la formación histórica de la burguesía, afirma que "Jorge Sorel es uno de los economistas modernos que mejor remarca y define el papel de los monasterios en la economía europea” (Mariátegui, 2007, pp. 4950), remitiendo a otra obra de Sorel: la Introduction à l'economie moderne de 1903.

Mariátegui también menciona a Sorel en una nota al pie, en el mismo ensayo, cuando afirma que en el Incario existió una forma de comunismo, así como podría llegar a existir en la sociedad moderna, aunque advierte que ambos comunismos presentarían rasgos muy diversos, ya que "la de los inkas fue una civilización agraria. La de Marx y Sorel es una civilización industrial” (2007, p. 63). Luego vuelve a referirse a Sorel cuando analiza la disolución de la propiedad comunal, a partir del advenimiento del régimen latifundista que destruyó, en Perú, no sólo un medio de satisfacción económica, sino además una institución social que conservaba la tradición y los sentimientos más preciados de la familia campesina indígena. Aquí, Mariátegui apela a Sorel para subrayar que la realización de los valores morales y espirituales, en la actividad económica, depende de los sentimientos que los trabajadores experimentan de acuerdo a la tarea que realizan (2007, p. 71), diferenciándose así el trabajo en el latifundio y en las tierras comunales. Citando otra vez la Introduction à l'economie moderne, la gravitación de Sorel le permite a Mariátegui poner el acento en la dimensión afectiva de los sujetos, en el marco de las relaciones de producción.

Otra mención al mito revolucionario de corte soreliano aparece en el ensayo "El problema del indio”. La totalidad de este texto se destina a desafiar las visiones tradicionales acerca del problema 
indígena, abriendo paso a un nuevo análisis crítico que centra su atención tanto en las relaciones de producción, desde el punto de vista económico, como en las fuerzas productivas, precisamente en el campesinado-indígena, en torno a su faceta psicológico-afectiva. En una extensa nota al pie, Mariátegui advierte que "no es la civilización, no es el alfabeto del blanco, lo que levanta el alma del indio. Es el mito, es la idea de la revolución socialista. La esperanza indígena es absolutamente revolucionaria” (2007, p. 26). Hay una reivindicación del indio en términos sociales, económicos y políticos, descartando el factor étnico y moral, pues "la miseria moral y material de la raza indígena aparece demasiado netamente como una simple consecuencia del régimen económico y social que pesa sobre ella desde hace siglos” (2007, pp. 26-27).

Más adelante en la obra, en el ensayo "El factor religioso”, Mariátegui remite al Sorel de las Reflexiones..., al abordar el mito como concepto movilizador de las multitudes. Allí parafrasea las ideas esbozadas previamente en "El hombre y el mito”, incluidas las referencias a la "Carta a Daniel Halévy”:

El pensamiento racionalista del siglo diecinueve pretendía resolver la religión en la filosofía. Más realista, el pragmatismo ha sabido reconocer al sentimiento religioso el lugar del cual la filosofía ochocentista se imaginaba vanidosamente desalojarlo. Y, como lo anunciaba Sorel, la experiencia histórica de los últimos lustros ha comprobado que los actuales mitos revolucionarios o sociales pueden ocupar la conciencia profunda de los hombres con la misma plenitud que los antiguos mitos religiosos (Mariátegui, 2007, p.: 160).

Además de diferenciar la religiosidad incaica respecto de los ritos católicos, en este ensayo Mariátegui subraya el sentimiento, la pasión y/o el misticismo de las masas indígenas, aunque adopta también una mirada crítica respecto de “los intentos de resucitar mitos pretéritos” que "resultan, enseguida, destinados al fracaso" (2010, p. 184), en la medida en que contradicen una concepción dinámica de la historia e implican una negación arqueologizante del proceso de dominación (y de mestizaje cultural) sostenido por siglos. El catolicismo se impuso sobre los ritos indígenas, pero sólo a medias, ya que éstos subyacen parcialmente en el imaginario colectivo del indio. Lo realmente importante no es el culto o el rito en sí, en su “pureza”, sino la religiosidad, aún conservada pese a la larga historia de la conquista y la colonia, y aún activa como factor que influye en la psicología del campesinado indígena:

El concepto de religión ha crecido en extensión y profundidad. No reduce ya la religión a una iglesia y un rito. $Y$ reconoce a las instituciones y sentimientos religiosos una significación muy diversa de la que ingenuamente le atribuían, con radicalismo incandescente, gentes que identificaban religiosidad y "oscurantismo” (Mariátegui, 2007, p. 134).

Mariátegui sostiene que "los rasgos fundamentales de la religión incaica son su colectivismo teocrático y su materialismo” (2007, p. 135) pues advierte que, en el pasado, el indio poseía, más que un sistema metafísico trascendente, un código moral aplicado a la acción, a su modo de vida concreto); por ende, la religión formaba parte de lo cotidiano y asequible, y "la religión y la política reconocían los mismos principios y la misma autoridad”(2007, p. 136), lo que conducía a que 
indefectiblemente los valores religiosos fueran en sí valores sociales. Por esto, la religión incaica no pertenecía propiamente al ámbito del credo individual, sino que era parte de una disciplina o ética social; era sobre todo un fenómeno público, colectivo, que incluía al Estado.

Tal como lo expresa al final de este ensayo, en convergencia con el enfoque materialista que lo guía, Mariátegui considera las formas eclesiásticas y las doctrinas religiosas como "peculiares e inherentes al régimen económico-social que las sostiene” (2007, p. 159). Por eso, pensar el Estado por separado respecto de la religiosidad incaica implica pensarlo en términos modernos, occidentales, realizando un reduccionismo etnocéntrico. Mariátegui advierte que, en términos de la idiosincrasia indígena, esta separación no tiene sentido, ya que la religión incaica precolombina no supone fines trascendentes sino más bien temporales y activos, así como también la organización del Estado no escapa al ámbito de la religión como práctica pura y exclusivamente social: las instituciones, las creencias y los ritos de los indios, en el período prehispánico, coincidían armónicamente con su desarrollo económico, abocado sobre todo a las tareas de un pueblo agrícola y colectivista, basado en el principio de la reciprocidad (2007, p. 137). Esto es sumamente valioso para Mariátegui porque implica que, en oposición a una actitud introspectiva, la religiosidad indígena promueve la acción y una forma de vida fundada en valores éticos y espirituales colectivos.

Así, al entender que “cada época quiere tener una intuición propia del mundo” (Mariátegui, 2010, p. 184), afirma que los mitos revolucionarios tienen la capacidad de representar el fervor y el entusiasmo que durante largo tiempo han encarnado en los mitos religiosos, pero sin que esto implique "resucitar mitos pretéritos" (lo cual sería contrario a su concepción dialéctica de la historia) (2010, p. 184). El Amauta aspira entonces a combinar esta religiosidad (activa sobre todo en las masas campesinas) y el potencial político del mito soreliano, para poner en marcha una transformación revolucionaria en el país $\underline{12}$.

Otras menciones a Sorel pueblan los Siete ensayos..., insistiendo en esta espiritualización del marxismo. Así por ejemplo en "El proceso de la literatura”, recupera el concepto soreliano de “elementos espirituales del trabajo” (Mariátegui, 2007, p. 291), cuando asegura que, más allá de procesos históricos concretos como la conquista o la implantación de los gamonales, el indio continúa conservando elementos típicos bien arraigados de su propia tradición, que subyacen a la cultura impuesta por los europeos: "El indio sigue viviendo su antigua vida rural. Guarda hasta hoy su traje, sus costumbres, sus industrias típicas. Bajo el más duro feudalismo, los rasgos de agrupación social indígena no han llegado a extinguirse” (2007, p. 291) (por otro lado, cabe señalar que, en esta cita, Mariátegui apela a la expresión “agrupación social indígena”, para denominar un instrumento social de resistencia de los trabajadores campesinos) $\underline{13}$. En el mismo ensayo, vuelve a aludir al mito soreliano cuando, al analizar la obra de Manuel González Prada, toma distancia respecto de esta figura (a pesar de la fuerte afiliación que sostiene): si el autor de "Nuestros indios" todavía exaltaba los mitos de "la Ciencia, la Razón, el Progreso" (es decir, "los mitos del siglo diecinueve”) $\frac{14}{}$, para Mariátegui el mito que debe embanderar el movimiento socialista en el presente es, en cambio, el de la revolución. 


\section{Algunas reflexiones finales}

Como puede verse en el desarrollo de este trabajo, Mariátegui recepciona y revaloriza el concepto de "mito revolucionario" de Sorel $\frac{15}{}$, pero a partir de una adecuación adaptativa del mismo, atenta a las particularidades socioculturales de Perú, articulando esa noción de mito con la sed de creencia que, según percibe Mariátegui, se mantiene viva especialmente en el campesinado indígena.

Por otro lado, es necesario subrayar otras diferencias entre ambos autores. El mito soreliano se mantiene en la abstracción, independientemente de lo que pueda considerarse como una huelga concreta, pues para este autor los mitos "no son descripciones de cosas, sino expresiones de voluntades” (Sorel, 2005, p. 90). Por eso, al hacer referencia a la huelga general no se habla de ninguna huelga en particular $\underline{16}$. Ésta Esta fomenta la esperanza de los proletarios, en el imaginario colectivo de la clase, de que podría llegar a concretarse un hecho de las proporciones suficientes como para desbaratar el sistema. En cambio, en el caso de Mariátegui, su posición respecto del valor y de la esperanza que despierta el mito revolucionario, en sus depositarios, depende del peso demográfico que el estrato indígena mantiene en la sociedad peruana, y del reconocimiento de la supervivencia de valores y creencias de matriz incaica, "residuales (en el sentido de Williams, 2009), pero aún vivos en el presente, y cuyo colectivismo puede empalmar con un proyecto socialista revolucionario. En esa supervivencia de elementos culturales, religiosos y éticos de las comunidades, Mariátegui entiende que anida una experiencia en franca oposición al capitalismo y al feudalismo gamonalista que la República aún sostiene. Y si el desarrollo de un movimiento socialista implica la formación de nuevas experiencias revolucionarias (que no reproduzcan los valores intrínsecos del capitalismo), las prácticas de las comunidades (y su valor como instituciones que fomentan la cooperación económica) no pueden pasarse por alto. Consciente de este papel central, Mariátegui realiza una "remisión hacia aquellos significados y valores que fueron creados en el pasado en sociedades reales y en situaciones reales, y que todavía parecen tener significación”, justamente porque, como advierte Williams para definir los elementos residuales, estos "representan áreas de la experiencia, la aspiración y el logro humanos que la cultura dominante rechaza, desprecia, contradice, reprime o incluso es incapaz de reconocer” (Williams, 2009, p. 164).

Mariátegui intenta crear así un nuevo espíritu socialista: contra el marxismo eurocéntrico de la dirigencia soviética, logra centrarse, desde el socialismo, en cuestiones oficialmente excluidas, tales como el peso de lo emotivo en la movilización de las masas, o la simpatía por el movimiento de los consejos de fábrica (al menos, en el caso de Italia), o las prácticas comunitarias indígenas en Perú.

En definitiva, a través de la recepción, apropiación y resignificación creativa de conceptos y valores que amplían el alcance del análisis marxista, puede entenderse el cruce --también creativo- que realiza el Amauta entre indigenismo y movimiento socialista.

\section{Notas}

1 Este libro es el resultado de una serie de artículos periodísticos aparecidos entre 1905 y 1906 en la revista francesa Le mouvement socialiste, editada en París entre 1899 y 1914, y luego compilados 
en libro en 1906. La primera edición en nuestro idioma, bajo el título de Reflexiones sobre la violencia, data de 1935. La traducción es de Luis Alberto Ruiz para la editorial Ercilla de Santiago de Chile. Podemos deducir por ende que Mariátegui lee la obra en su idioma original, ya que fallece en 1930.

$\underline{2}$ Editados por primera vez en 1928 por la Editorial Minerva de Lima.

$\underline{3}$ La afirmación de Paris sobre la constancia de la recepción de ideas sorelianas a la largo de toda la obra de Mariátegui, se ve respaldada si se tienen en cuenta, por ejemplo, la conferencia "Elogio de Lenin”, pronunciada en la Universidad Popular González Prada en 1924, y compilada póstumamente en Historia de la crisis mundial (1986); la publicación en la revista Amauta -en 1928- de uno de los apéndices de las Reflexiones... de Sorel, llamado "Defensa de Lenin”, y escrito originalmente por su autor en 1919 para incluirlo en la cuarta edición de la obra (1920); o las diversas citas explícitas y alusiones, presentes en los Siete ensayos..., obra principal del autor peruano.

4 Este trabajo se centra en el mito a partir del pensamiento de Sorel y su influencia en la obra mariateguiana. No obstante, para un enfoque centrado en un racconto histórico del mito político, que analice la evolución de este concepto en la historia de la filosofía política -incluso retomando a Sorel como un autor fundamental y a Lukács, por ejemplo, como uno de sus mayores críticos-, ver Bonazzi (cf. en Bobbio-Matteucci-Pasquino, 2002, pp. 976-985).

$\underline{5}$ Esta obra es publicada por su autor en la editorial Alcan de París, en 1895. Su primera edición en castellano, con el nombre de Psicología de las multitudes, aparece en 1911 por el sello editor Daniel Jorro de Madrid, traducida por Juan Manuel Navarro de Palencia.

$\underline{6}$ Véase, por ejemplo, Sorel (2005, p. 18). Aquí el autor se expresa en torno a las posibilidades de éxito de una huelga, en estrecha relación con las posibilidades de los sindicatos de representar o formular las demandas de los trabajadores ante el sector empresarial.

Z La importancia del pensamiento de González Prada para Mariátegui puede rastrearse en el ensayo "Proceso de la literatura” en los Siete ensayos..., cuando el Amauta analiza ciertos aspectos del posicionamiento político de este autor. Véase Mariátegui (2007, pp. 212-221).

8 Realizar un análisis más detallado y crítico de la relación de Mariátegui y su pensamiento -así como del Partido Socialista Peruano que funda en 1928- con los últimos momentos de la II Internacional y los primeros de la III Internacional, es un esfuerzo que, aunque valioso, excede a los objetivos de este trabajo, en el que sólo puede realizarse una acotada mención. Para considerar trabajos que hayan abordado esta problemática -además de lo que concierne a la relación del desarrollo teórico del marxismo a escala internacional con las elaboraciones propias de América Latina- pueden verse el de Kohan (2000) o el de Löwy (2007).

9 Para un análisis más detenido al respecto ver Beigel (2003, pp. 144-157).

$10 \mathrm{Al}$ respecto véase Bustelo y Domínguez Rubio (2015).

11 Un punto de vista acorde a este que se expresa respecto de Mariátegui puede verse en Angenot (2010b), cuando analiza la discursividad propia del socialismo y su propaganda política, destinada a promover en las masas trabajadoras la búsqueda de la organización y la intervención en el plano de 
la política. También el Angenot (2000) se encarga de abordar de qué manera, bajo qué términos, se manifiesta esa discursividad socialista en tanto discurso militante.

12 Un punto de vista similar puede verse en Flores Galindo (1994). Allí el historiador peruano analiza la capacidad movilizadora que tienen en los pueblos andinos, desde los momentos posteriores a la conquista española, ciertos mitos o utopías propios de sus tradiciones originarias, como elementos que operan en el plano afectivo-psicológico y pueden funcionar como puentes hacia la organización política, con miras a un proyecto socialista transformador.

13 Debe destacarse que cuando Mariátegui se expresa en torno a los elementos de la sociedad y la cultura indígena, que perviven aún en la fase republicana del Perú, piensa en dos cuestiones centrales. Por un lado, hace referencia a la religiosidad, es decir, al sentimiento místico que genera la pertenencia a una determinada religión; sentimiento que por cierto tiene características movilizadoras y tendientes a la acción colectiva, puesto que la religión incaica más que una tendencia introspectiva propicia una ritualidad colectiva (véase, por ejemplo, el ensayo "La religión del Tawantinsuyo", para un análisis de la religiosidad indígena y su subsistencia desde el comienzo del avance del catolicismo en el período posconquista). Por otro lado, el intelectual peruano se refiere al colectivismo económico, a la propiedad comunal de la tierra y a una unidad de desarrollo económico, social y cultural fundamental para la civilización andina como lo es el ayllu. En varios pasajes de los Siete ensayos... se describen rasgos de esta organización, así como también de su resistencia ante la implantación del modelo de producción gamonalista (véase, por ejemplo, el ensayo "El problema de la tierra”).

14 Para Mariátegui, González Prada es una suerte de intelectual romántico a pesar del positivismo. Además, “en González Prada subsiste, intacto en su osadía, el jacobino” (Mariátegui, 2007, p. 217). Sin dudas, la lectura de su ensayo "Nuestros indios” (1904), entre otros materiales, lleva a Mariátegui a considerar a este pensador vinculado al anarquismo como un verdadero padre simbólico del socialismo y del indigenismo peruanos. Al respecto ver Melgar Bao (2006).

15 Es necesario aclarar que, en este trabajo, tomamos aquellas cuestiones del pensamiento de Sorel -en particular su concepto de mito revolucionario, estrechamente ligado a sus Reflexiones...- que son revalorizadas desde movimientos o autores de izquierda como Mariátegui. Sin embargo, ciertas ideas sorelianas son recepcionadas también por la derecha política, e incluso pasan a estar emparentadas con el fascismo, aunque el análisis de estas derivas excede los objetivos de este trabajo. Para una crítica a Sorel, de acuerdo a la relación de su posicionamiento irracionalista con respecto al desarrollo de posturas asociadas al fascismo véase, por ejemplo, Lukács (1976).

16 Así, por ejemplo, es difícil definir cuáles serían, para Sorel, las huelgas que se aproximarían más al mito de la huelga general. Ya que, tal como afirma Berlin (en Sorel, 2005, p. 42), "no tuvo nada favorable que decir de las huelgas generales, orientadas a la obtención de concesiones concretas, que estallaron durante su fase más sindicalista en Bélgica en 1904”. Por ende, la calificación de una huelga concreta y sus caracteres primordiales es algo que en las Reflexiones... queda pendiente. 


\section{Bibliografía}

Angenot, M. (2000). Les grands récits militants des XIXe et XXe siècles. Religions de l'humanité de l'histoire. Paris: L'Harmattan.

Angenot, M. (2010a). El discurso social. Buenos Aires: Siglo XXI Editores.

Angenot, M. (2010b). La propaganda socialista. Elementos de retórica y pragmática. En Interdiscursividades. De hegemonías y discursos (pp. 151-214). Córdoba: UNC.

Aricó, J. M. (comp.). (1980). Mariátegui y los orígenes del marxismo latinoamericano. México DF: Siglo XXI.

Aricó, J. M. (2010). Marx y América Latina. Buenos Aires: Fondo de Cultura Económica.

Beigel, F. (2003). El itinerario y la brújula. El vanguardismo estético-político de José Carlos Mariátegui. Buenos Aires: Biblos.

Beigel, F. (2006). La epopeya de una generación y una revista. Las redes editoriales de José Carlos Mariátegui en América Latina. Buenos Aires: Biblos.

Berlin, I. [1971] (2005). Prefacio. En Sorel, G., Reflexiones sobre la violencia (pp. 7-58). Madrid: Alianza Editorial.

Bonazzi, T. (2002). Mito político. En Bobbio, N., Matteucci, N. y Pasquino, G. (eds.), Diccionario de política (pp. 976-985). México DF: Siglo XXI Editores.

Bourdieu, P. (2007). Intelectuales, política y poder. Buenos Aires: Eudeba.

Bustelo, N. y Domínguez Rubio, L. (2015). Vitalismo libertario y Reforma Universitaria. Los textos filosófico-políticos del joven Carlos Astrada (1919-1924). Políticas de la Memoria, $16 .$.

Castilla, M. (2012a). Arielismo, mitos y marxismo espiritualista en el pensamiento de José Carlos Mariátegui. En VII Jornadas de Sociología de la Universidad Nacional de La Plata. "Argentina en el escenario latinoamericano actual: debates desde las ciencias sociales”, La Plata: UNLP. Recuperado de http://jornadassociologia.fahce.unlp.edu.ar/actas/Castilla.pdf.

Flores Galindo, A. (1994). Buscando un Inca. Identidad y utopía en los Andes. Lima: Editorial Horizonte.

Gramsci, A. (2006). Antología. Buenos Aires: Siglo XXI Editores.

Kohan, N. (2000). Los combates de Mariátegui. En De Ingenieros al Che. Ensayos sobre el marxismo argentino y latinoamericano (pp. 95-111). Buenos Aires: Biblos.

Kersffeld, D. (2004). Georges Sorel: apóstol de la violencia. Buenos Aires: Ediciones Del Signo.

Lagos Rojas, F. A. (2010). Los siete ensayos de Mariátegui como una crítica de la razón oligárquica. En Weinberg, L., Estrategias del pensar. México DF: CIALC-UNAM.

Löwy, M. (1998). Marxismo y romanticismo en la obra de José Carlos Mariátegui. En Revista 
Herramienta, 8. Recuperado de http://www.herramienta.com.ar/revista-herramienta-n-8/marxismoy-romanticismo-en-la-obra-de-jose-carlos-mariategui.

Löwy, M. (2007). El marxismo en América Latina. Antología, desde 1909 hasta nuestros días. Santiago de Chile: LOM Ediciones.

Lukács, G. (1976). El asalto a la razón. La trayectoria del irracionalismo desde Schelling hasta Hitler. México DF: Fondo de Cultura Económica.

Mariátegui, J. C. (1970). El alma matinal y otras estaciones del hombre de hoy. Lima: Biblioteca Amauta.

Mariátegui, J. C. (2007). Siete ensayos de interpretación de la realidad peruana. Caracas: Biblioteca Ayacucho.

Mariátegui, J. C. (2010). La tarea americana. Buenos Aires: CLACSO-Prometeo Libros.

Melgar Bao, R. (2006). América Latina en el pensamiento de Manuel González Prada. En Tauzin, I. (ed.), Manuel González Prada: Escritor de dos mundos. Actas del Coloquio Internacional ERSALAMERIBER EA 3656 (pp. 185-200). Lima: Instituto Francés de Estudios Andinos.

Paris, R. y Villaverde Alcalá-Galiano, L. (1980). III. Mariátegui, ¿̇soreliano o marxista? En Aricó, J. (comp.), Mariátegui y los orígenes del marxismo latinoamericano (pp. 117-161). México D F: Siglo XXI.

Quijano, A. (2007). Prólogo. En Mariátegui, J. C., Siete ensayos de interpretación de la realidad peruana. Caracas: Biblioteca Ayacucho.

Sazbón, J. (2002). Filosofía y revolución en los escritos de Mariátegui. En Historia y representación (pp. 114-155). Bernal: Universidad Nacional de Quilmes.

Sorel, G. (2005). Reflexiones sobre la violencia. Madrid: Alianza Editorial.

Terán, O. (1986). Mariátegui: la nación y la razón. En En busca de la ideología argentina (pp. 99129). Buenos Aires: Catálogos Editora.

Williams, R. (2009). Marxismo y literatura. Buenos Aires: Las Cuarenta.

Williams, R. (2003). Palabras clave. Un vocabulario de la cultura y la sociedad. Buenos Aires: Nueva Visión.

Zucconi, M. (2015). La formación teórica de José Carlos Mariátegui: Espiritualización y heterodoxia del marxismo (tesis de grado). Universidad Nacional de La Plata. Facultad de Humanidades y Ciencias de la Educación, La Plata, Argentina. Recuperada de http://www.memoria.fahce.unlp.edu.ar/tesis/te.1210/te.1210.pdf. 